\title{
Percutaneous closure of an adult patent ductus arteriosus
}

H.M.M. Al Hashimi, A.J. Wardeh, W.R.M. Aangevaeren, F.W.A. Verheugt

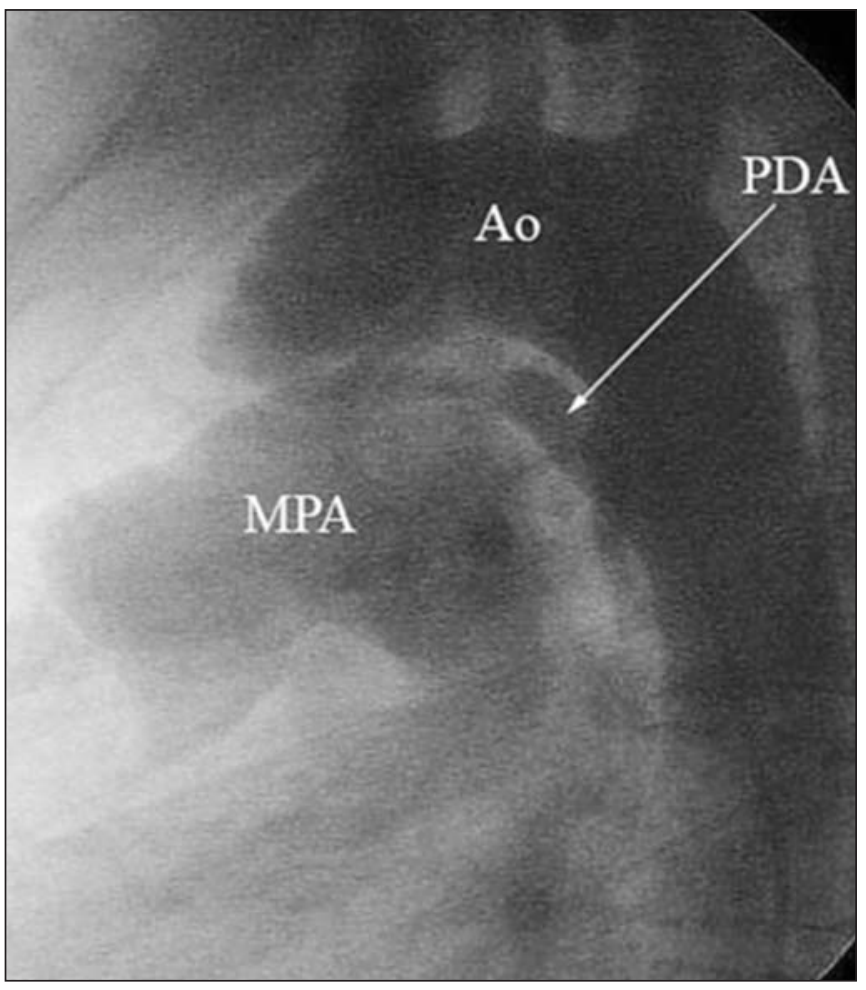

Figure 1. Aortagram demonstrating the PDA (arrow). Ao=aorta, $P D A=$ patent ductus arteriosus, $M P A=$ main pulmonary artery.

23-year-old asymptomatic male was referred to our outpatient clinic because of an incidentally discovered grade III continuous machinery murmur at the third intercostal space on the left sternal edge.

\section{H.M.M. Al Hashimi}

Department of Cardiology, Slotervaart Hospital, Amsterdam, the Netherlands

\section{A.J. Wardeh}

\section{W.R.M. Aangevaeren}

F.W.A. Verheugt

Department of Cardiology, Radboud University Medical Centre, Nijmegen, the Netherlands

\section{Correspondence to: H.M.M. Al Hashimi}

Department of Cardiology, Slotervaart Hospital,

P.O. Box 90440, 1006 BK Amsterdam, the Netherlands

E-mail: hishamalhashimi@hotmail.com

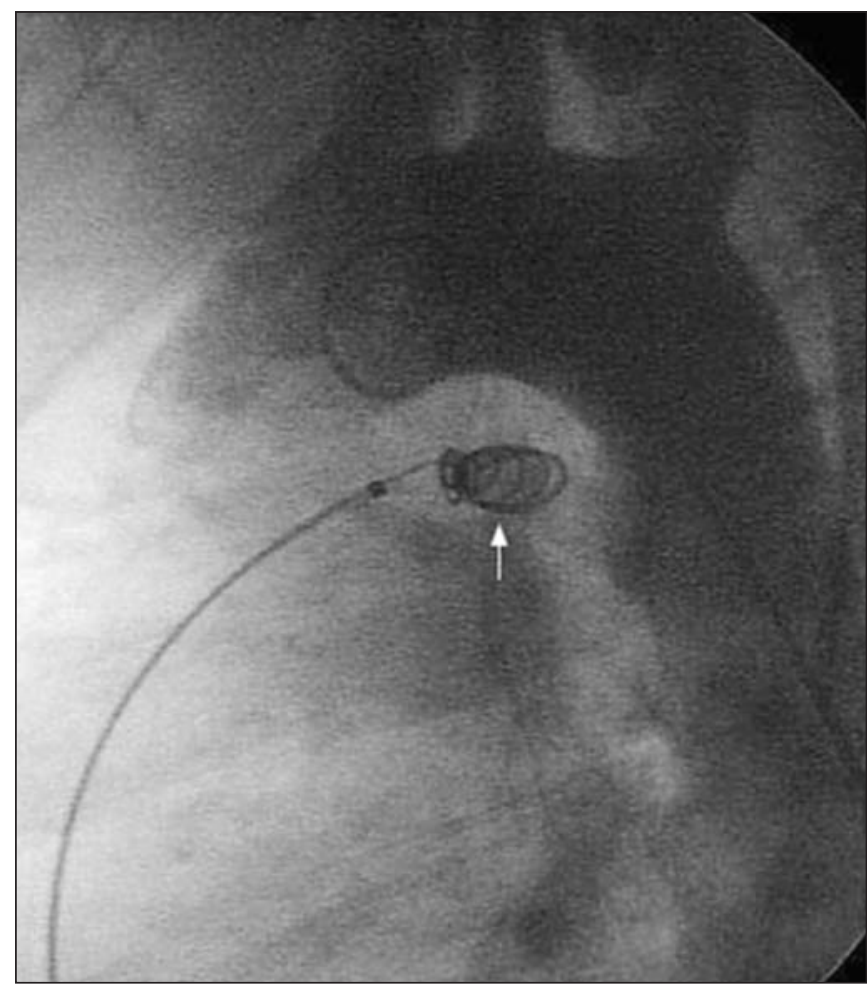

Figure 2. Aortagram after percutaneous coil occlusion. One embolisation coil has been positioned across the ductus arteriosus (arrow).

The echocardiography showed the presence of a patent ductus arteriosus (PDA). An aortography confirmed the PDA (figure 1). As patients with PDA are at a high risk of developing infective endocarditis, heart failure and pulmonary hypertension, ${ }^{1}$ it was decided to treat it by percutaneous coil occlusion (figure 2 ).

\section{Discussion}

The ductus arteriosus (DA) is a vascular connection between the main pulmonary artery and the aorta distal to the subclavian artery. During the foetal life, the DA diverts blood away from the pulmonary bed. After birth, it undergoes active constriction and closure. If the DA fails to close completely, a PDA will develop. The incidence of PDA is 0.02 to $0.04 \%$ with a female predominance. ${ }^{2}$ The clinical presentation depends upon the size of the PDA. Small PDAs may go 
undetected in infancy, with no identifiable symptoms. Large PDAs often present with symptoms and signs of heart failure. The most obvious sign is the presence of a continuous, machinery, murmur in the left infraclavicular region. ${ }^{1}$ Closure of the PDA can be performed by a medical, surgical and transcatheter approach. The medical approach (indomethacin) is the first therapy in premature infants. Surgical ligation is the standard technique for treating infants who fail to respond to indomethacin. Percutaneous coil occlusion has been accepted for the treatment of small and medium-sized PDAs and is becoming the treatment of choice for most children and adults with an efficacy of 95\% at one year follow-up. . $^{3,4}$

\section{References}

1 Campbell M. Natural history of persistent ductus arteriosus. $B r$ Heart J 1968;30:4

2 Mullins CE. Patent ductus arteriosus. In: The Science and practice of pediatric cardiology, Garson A, Bricker JT, Mcnamara DG (Eds), Lea Febiger, Philadelphia 1990, p 1055.
3 Shim D, Fedderly RT, Beekman RH 3rd, et al. Follow-up of coil occlusion of patent ductus arteriosus. J Am Coll Cardiol 1996;28: 207.

4 Magee AG, Huggon IC, Seed PT, Qureshi SA. Transcatheter coil occlusion of the arterial duct. Results of the European Registry. Eur Heart J 2001;22:1817.

In this section a remarkable 'image' is presented and a short comment is given.

We invite you to send in images (in triplicate) with a short comment (one page at the most) to Bohn Stafleu van Loghum, PO Box 246, 3990 GA Houten, e-mail: l.jagers@bsl.nl.

'Moving images' are also welcomed and (after acceptance) will be published as a Web Site Feature and shown on our website: www.cardiologie.nl

This section is edited by M.J.M. Cramer and J.J. Bax. 